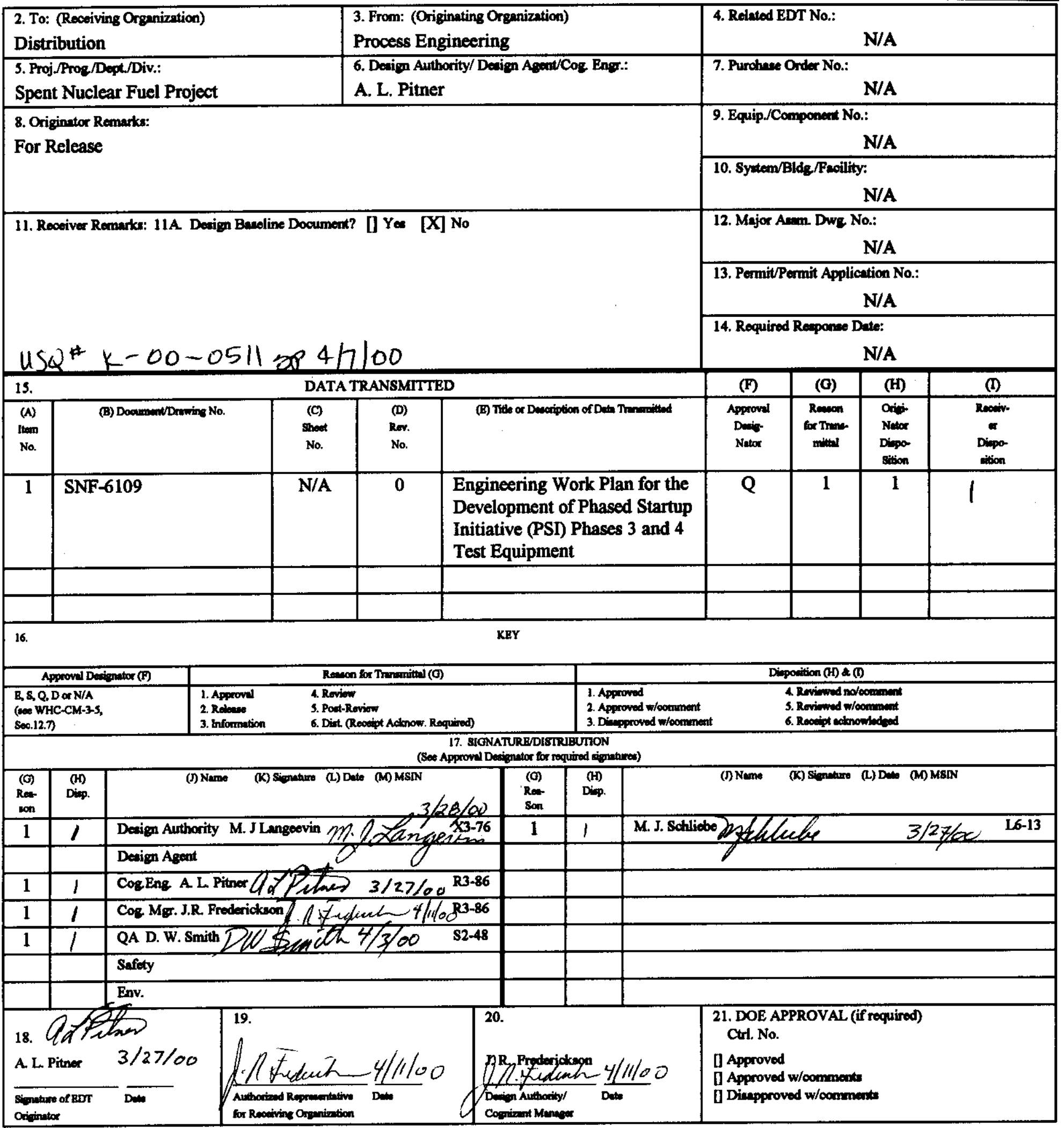


SNF-6109

Revision 0

\section{Engineering Work Plan for the Development of Phased Startup Initiative (PSI) Phases 3 and 4 Test Equipment}

Prepared for the U.S. Department of Energy Assistant Secretary for Environmental Management

Project Hanford Management Contractor for the

U.S. Department of Enorgy under Contract DE-AC06-86RL13200

Fluor Hanford

P.O. Box 1000

Richland, Washington 
SNF-6109

Revision 0

EDT 629010

\title{
Engineering Work Plan for the Development of Phased Startup Initiative (PSI) Phases 3 and 4 Test Equipment
}

\author{
A. L. Pitner \\ Fluor Hanford \\ Date Published \\ March 2000
}

Prepared for the U.S. Department of Energy

Assistant Secretary for Environmental Management

Project Henford Managoment Contractor for the

U.S. Department of Energy under Contract DE-AC06-96RL13200

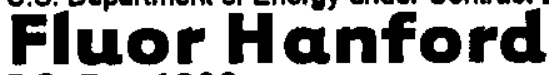

P.O. Box 1000

Richland, Washington
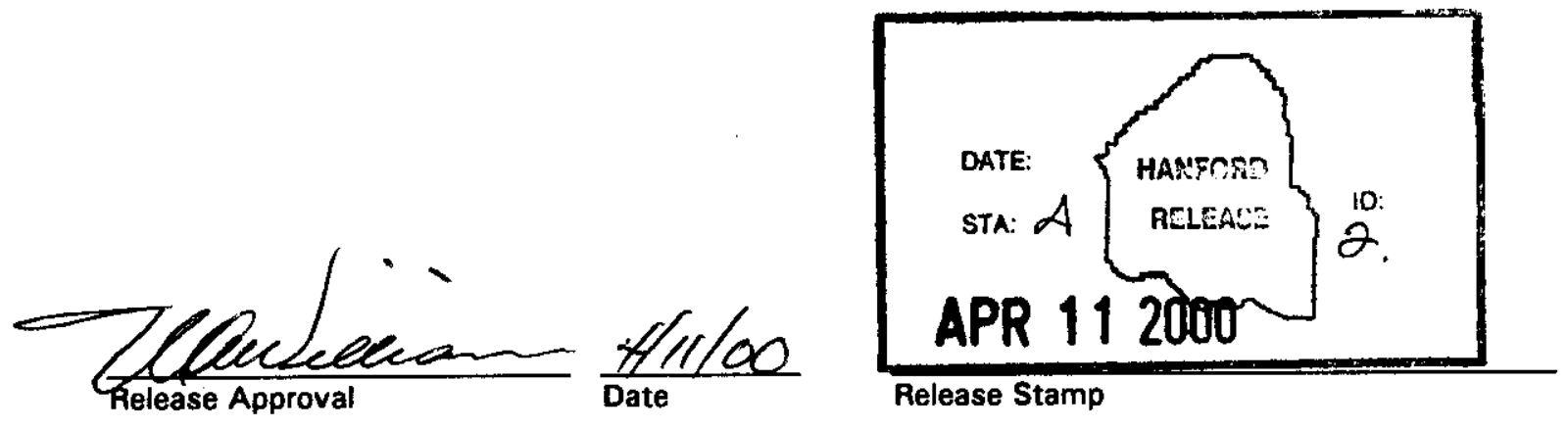

Release Stamp 


\section{TRADEMARK DISCLAMMER}

Reference herein to any specific commercial product, proceses,

or servlce by trade name, trademark, manufacturer, or

otherwise, does not necesearly conetitute or imply its

endorsement, recommendation, or favoring by the United

States Government or any agency thereof or its contractors or subcontractors.

This report has been reproduced from the beat available copy. Avallable in paper copy and microfiche.

Available electronically at http://www.doe.gov/bridge. Avallable for a procesesing fee to the U.S. Department of Energy and lts contractors, in paper, from:

U.S. Department of Energy

Orfice of Scientific and Technical Information

P.O. Box 62

Oak Ridge, TN 37831-0062

phone: 865-576-8401

fax: 865-576-5728

email: reports@adonis.oeti.gov(423) 576-8401

Printed in the United States of Amorica

Total Pages:

SNF -6109

Revo. 


\section{ENGINEERING WORK PLAN FOR THE DEVELOPMENT OF PHASED STARTUP INITITIATIVE (PSI) PHASES 3 AND 4 TEST EQUIPMENT}

\subsection{INTRODUCTION}

A number of tools and equipment pieces are required to facilitate planned test operations during Phases 3 and 4 of the Phased Startup Initiative (PSI). These items will be used in assessing residual canister sludge quantities on cleaned fuel assemblies, sorting coarse and fine scrap fuel pieces, assessing the size distribution of scrap pieces, loading scrap into a canister, and measuring the depth of the accumulated scrap in a canister. This work plan supercedes those previously issued (Pitner 2000a, Pitner 2000b) for development of several of these test items. These items will be considered prototype equipment until testing has confirmed their suitability for use in $\mathrm{K}$ West Basin. The process described in AP-EN-6-032 will be used to qualify the equipment for facility use. These items are considered non-OCRWM for PSI Phase 3 applications.

The safety classification of this equipment is General Service, with Quality Level 0 (for PSI Phase 3). Quality Control inspections shall be performed to verify basic dimensions and overall configurations of fabricated components, and any special quality control verifications specified in this work plan (Section 3.1.5). These inspections shall serve to approve the test equipment for use in $\mathrm{K}$ West Basin (Acceptance Tag).

This equipment is for information gathering only during PSI Phases 3 and 4 activities, and will be discarded at the completion of PSI. For equipment needed to support actual production throughput, development/fabrication/testing activities would be more rigorously controlled.

\subsection{SCOPE}

\subsection{Objectives}

The allowable limit of residual canister sludge remaining on cleaned fuel assemblies is $1.4 \mathrm{~cm}^{3}$ (Pitner 2000c). It is anticipated that a general visual inspection of the sludge inventory after fuel assembly separation will usually suffice in assessing whether this limit has been exceeded. However, borderline cases may be encountered where a more quantitative method of evaluating the observed sludge quantity would be useful. It is proposed to develop an adapter that fits on the end of the secondary cleaning station vacuum wand that would suction up the observed sludge into a known volume in order to better assess the quantity of sludge present.

Fuel scrap pieces will be separated into categories of coarse scrap ( 1 to 3 inches) and fine scrap (less than 1 inch) to support assessment of fine and coarse scrap basket loading quantities. A sieve device will be provided to assist in making this segregation during PSI Phases 3 and 4 testing. 
Size assessments of fuel scrap pieces will be performed during PSI Phases 3 and 4 to provide information pertinent to production run scrap generation quantities and size distributions. To facilitate this process, a grid plate shall be fabricated on which scrap pieces can be distributed for scrap size evaluations. This grid plate will also serve as a device for transferring fuel scrap to scrap canisters for storage in $\mathrm{K}$ West Basin after completion of PSI.

In order to estimate packing densities of fuel scrap pieces in the scrap canisters, it is necessary to know the depth of the scrap inventory in the scrap canister. A simple depthmeasuring device will be provided to allow nominal measurements of scrap depths in the canister barrels.

The testing will be performed in the 305 Building in the 300 Area. The end use of this equipment will be in $\mathrm{K}$ West Basin, so the test items must be fabricated to be compatible with that environment.

\subsection{Deliverables}

The following items are to be provided along with as-built drawings of each of the items.

1) Sludge Collection Tray to capture sludge dislodged from the fuel assembly when the inner element is separated from the outer element.

2) Sludge Pickup Adapter that can be attached to the vacuum wand strainer tip to permit suctioning up sludge present in the Sludge Collection Tray.

3) Adapter Installation Fixture that expedites attachment and detachment of the Sludge Pickup Adapter to the vacuum wand strainer tip.

4) 1-inch Sieve Module for use in separating coarse and fine scrap.

5) Grid Plate for use in assessing the size distributions of fuel scrap pieces. The Grid Plate will also serve as a transfer medium for loading the scrap pieces into a scrap canister.

6) Scrap Depth Measurement Tool for providing a nominal indication of the scrap depth in a canister barrel. 
SNF-6109, Rev. 0

\subsection{DESCRIIPTION}

\subsection{Physical Description}

\subsubsection{Sludge Collection Tray}

A flat tray will be used to capture canister sludge that is dislodged from the fuel elements during assembly separation and examination. The inner fuel element will be pushed into this tray by the hydraulic ram separation mechanism on the process table. A conceptual configuration of the tray is shown in Figure 1. The tray is to be fabricated from stainless steel. The tray is sized to fit into the separation station and to capture the inner fuel element. After fuel assembly separation, the inner element will be removed from the tray and the tray will be visually inspected for canister sludge content. The tray will be vacuumed clean before each fuel assembly separation and inspection operation.

The final tray design shall be documented in an as-built drawing.

\subsubsection{Sludge Pickup Adapter}

The sludge pickup adapter will be affixed to the vacuum wand strainer tip as a friction fit. The configuration of this arrangement is depicted in Figure 2. The vacuum action from the wand will also help keep the adapter affixed to the strainer tip during operation. The testing in 305 building shall use the prototype vacuum wand, with a nominal water flow suction rate of $80 \mathrm{gpm}$. The usual sludge simulant (standard mixture of sand, flyash, and tungsten powder) shall be used in the development testing for the sludge pickup adapter.

A conceptual design for the sludge pickup adapter is shown in Figure 3. Based on anticipated laboratory testing results, it is expected that the surface area of the filter may have to be increased to compensate for plugging effects. Also, the bypass flow areas (where the adapter attaches to the wand tip) may have to be varied to provide appropriate suction at the tip of the adapter.

The design developed shall be capable of suctioning up at least $75 \%$ of the allowable $1.4 \mathrm{~cm}^{3}$ sludge volume limit for each fuel assembly before plugging and ceasing to vacuum any more. This functionality would assist in performing fuel cleanliness inspections during PSI Phases 3 and 4.

The final adapter design shall be documented in an as-built drawing.

\subsubsection{Adapter Installation Fixture}

In K West Basin applications, the sludge pickup adapter will be remotely affixed to the end of the vacuum wand. A fixture is required to facilitate this installation. The fixture shall hold the adapter while the vacuum wand is pushed downward into it to affix it. A 
means for detaching the adapter is also required, such as a lip to capture the adapter while the vacuum wand is pulled upward to disengage it. Accordingly the fixture must be heavy enough to sustain the upward force required to dislodge the adapter. The fixture shall be fabricated from stainless steel. The final design shall be documented in an asbuilt drawing.

\subsubsection{1-inch Sieve Module}

A commercial 1-inch sieve unit with 8 -inch nominal diameter shall be procured. The sieve material shall be stainless steel. Some type of handle shall be attached to the sieve module to facilitate manipulator grappling. The final design shall be documented in an as-built drawing.

\subsubsection{Grid Plate}

The grid plate shall be fabricated in accordance with Figure 4. Dimensions shown in Figure 4 are fixed dimensions, while those not shown (e.g., bail sizes) are arbitrary. The grid plate also serves as a vehicle for loading fuel scrap into scrap canisters by positioning it over a canister barrel and tilting the back end upward to pour the scrap into the barrel.

The grid on the plate shall be formed by machined or scribed grooves in the anodized blue aluminum plate. Depending on the visibility of the machined grooves, they may be filled with paint to enhance visibility. This grid plate will be used in assessing the size distribution of fuel scrap pieces during PSI Phases 3 and 4. The spacing between lines on the grid plate shall be verified to be $1 \pm 1 / 32$ inch.

The final design of the grid plate shall be documented in an as-built drawing.

\subsubsection{Scrap Depth Measurement Tool}

In order to estimate the packing density of scrap in a scrap canister, the depth of scrap in a canister must be known. A modified rule shall be fabricated in accordance with the basic concept shown in Figure 5 for this purpose. The intended use of this device is to measure the scrap depth in a canister barrel to an accuracy of \pm 1 inch. The rule shall have high visibility $1 / 4$-inch markings. The final design of the tool shall be documented in an as-built drawing.

\subsection{Engineering Tasks}

Development of the sludge pickup adapter is the only item in this test equipment package that requires engineering work to be performed. 
Appropriate pumping equipment and associated hoses and connections shall be installed in the 305 Building Cold Test Facility to perform the developmental testing. A flowmeter shall be included in the pumping system. The pumping system shall be capable of controlling the flow rate at $80 \pm 10 \mathrm{gpm}$

Prescribed amounts of standard canister sludge simulant shall be loaded into the sludge collection tray and placed underwater for vacuum testing. The tray shall be cleaned between test runs.

It is anticipated that plugging of the filter in the sludge pickup adapter will cause suctioning to diminish as sludge is vacuumed into the collection chamber. Ideally, the full limiting volume of $1.4 \mathrm{~cm}^{3}$ would be collected before the filter plugged, but even if a large majority (e.g., $\geq 75 \%$ ) of this limit were collected before plugging, that would be considered useful information in assessing the total sludge quantity present. The objective is to develop a design that reliably collects most of the limiting volume. This likely would involve varying the geometry of the collection chamber in the sludge pickup adapter.

\subsection{Verification}

Once a satisfactory design has been developed through prototype testing and appropriate design adjustments, a formal acceptance test shall be performed on the final design. The test shall be performed in the 305 Building water pool and monitored using an underwater video camera. The test shall demonstrate the capability to attach the sludge pickup adapter to the vacuum wand, and also detach it after vacuuming tests are completed. The underwater vacuuming test shall consist of vacuuming a measured $1.4 \mathrm{~cm}^{3}$ volume of sludge simulant from the collection tray positioned in the water pool. The relative amount of sludge simulant successfully vacuumed up shall be visually estimated and recorded. The test results shall be documented in an Acceptance Test Report and shall be reviewed by a Quality Assurance representative.

Following the demonstrated functionality of the sludge pickup adapter, $\mathrm{K}$ Basin operators will be familiarized with use of the device in the 305 Building test facility. This will involve underwater sludge pickup activities using the prototype adapter and collection tray containing simulated sludge.

\subsection{Procurement Tasks}

These items are General Service and do not require special controls for procurement activities. 


\subsection{Installation Tasks}

Once a satisfactory design has been developed and demonstrated, installation of the sludge pickup adapter onto the vacuum wand strainer tip by $K$ Basins Operations personnel shall be considered a routine operation. A new sludge pickup adapter shall be installed for each inspection occasion.

\subsection{ORGANIZATION}

Process Engineering has overall responsibility for this task, and will issue this work plan and interact with the performing organization in the development of the sludge pickup adapter. The manager of Process Engineering is J. R. Frederickson, and the Cognizant Engineer for this effort is A. L. Pitner.

The actual development testing will be performed by Engineering Laboratories in the 305 Building facilities. Manager of Engineering Laboratories is M. J. Schliebe, and the Test Engineer for this task is J. W. Oliver. This organization will also issue the Acceptance Test Report upon completion of the activity.

\subsection{SCHEDULE}

The completion target for these activities is the end of March 2000 to support a PSI Phase 3 Readiness Assessment in April 2000.

\subsection{COST ESTIMATE}

Unknown factors such as actual development testing time required to achieve a functional design do not permit an accurate estimate of the total cost. For planning purposes based on a facility charge-out rate of $\$ 90 /$ hour for exempt support and $\$ 70 /$ hour for technician support, the estimated cost is $\$ 25,000$. The CACN that supports this activity is 105355 and the COA is BA40

\subsection{QUALITY ASSURANCE}

Quality Assurance approval of this work plan is required.

Equipment will be fabricated, installed and operated by 305 Building personnel in accordance with approved procedures.

The results of the Acceptance Test for the Sludge Pickup Adapter will be reviewed and approved by a qualified Quality Assurance representative. 
Quality Assurance will verify that the fabricated test items conform to the as-built drawings, and approve them for use in $\mathrm{K}$ West Basin (Acceptance Tag). The drawing number for these test items is H-1-84840.

\subsection{REFERENCES}

Pitner, A. L., 2000a, Engineering Work Plan for Development of Sludge Pickup Adapter for Fuel Cleanliness Inspections, SNF-5531, Rev. 0, Fluor Hanford, Richland, Washington.

Pitner, A. L., 2000b, Engineering Work Plan for Development of Sludge Pickup Adapter for Fuel Cleanliness Inspections, SNF-5531, Rev. 0A, Fluor Hanford, Richland, Washington.

Pitner, A. L., 2000c, Planning Document for Spent Nuclear Fuel Cleanliness Inspection Process, HNF-5271, Rev. 0, Fluor Daniel Hanford, Inc. Richland, Washington 
SNF-6109, Rev. 0

Figure 1. Canister Sludge Collection Tray.

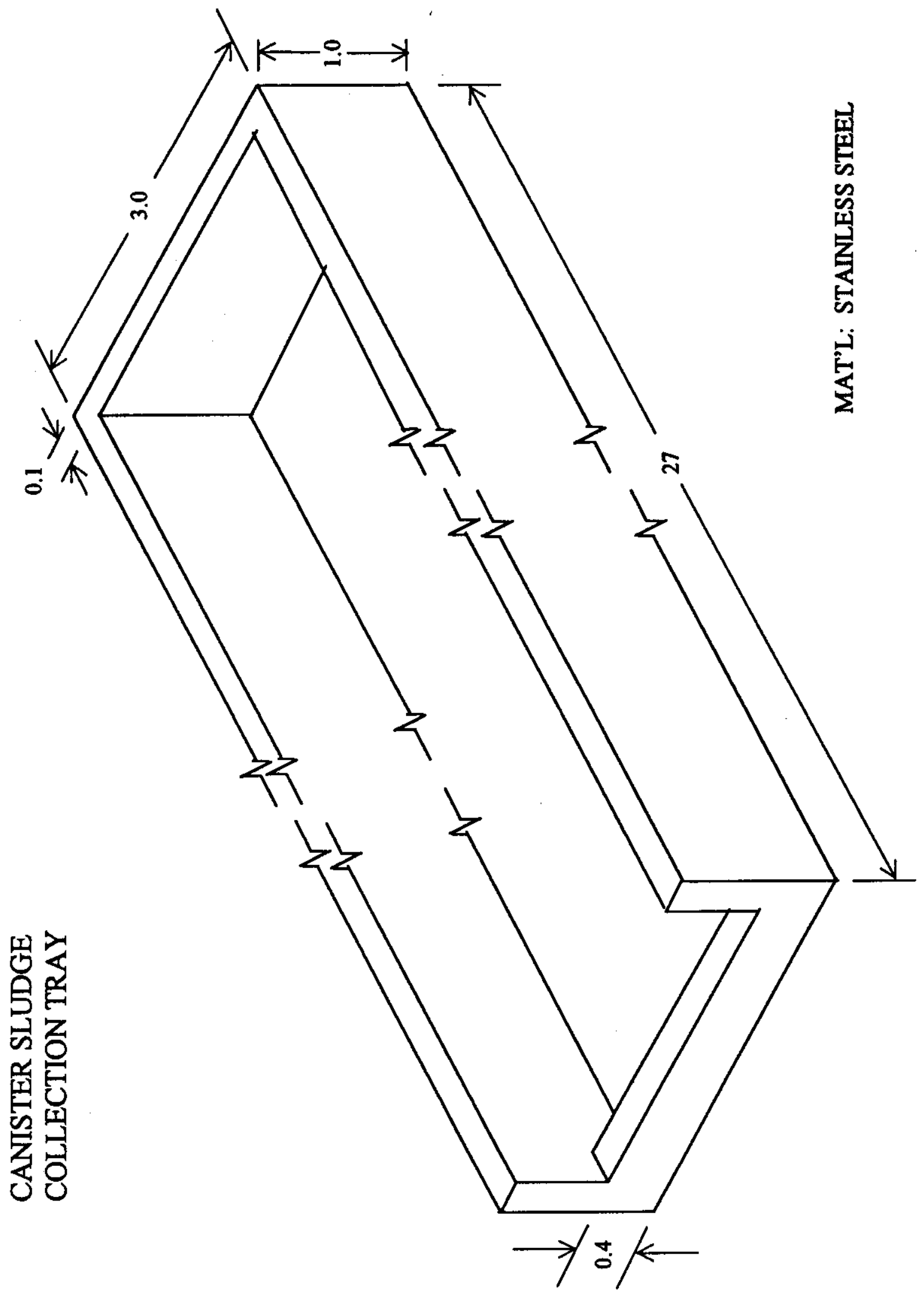




\section{SNF-6109, Rev. 0}

Figure 2. Vacuum Wand Strainer Tip and Sludge Pickup Adapter.
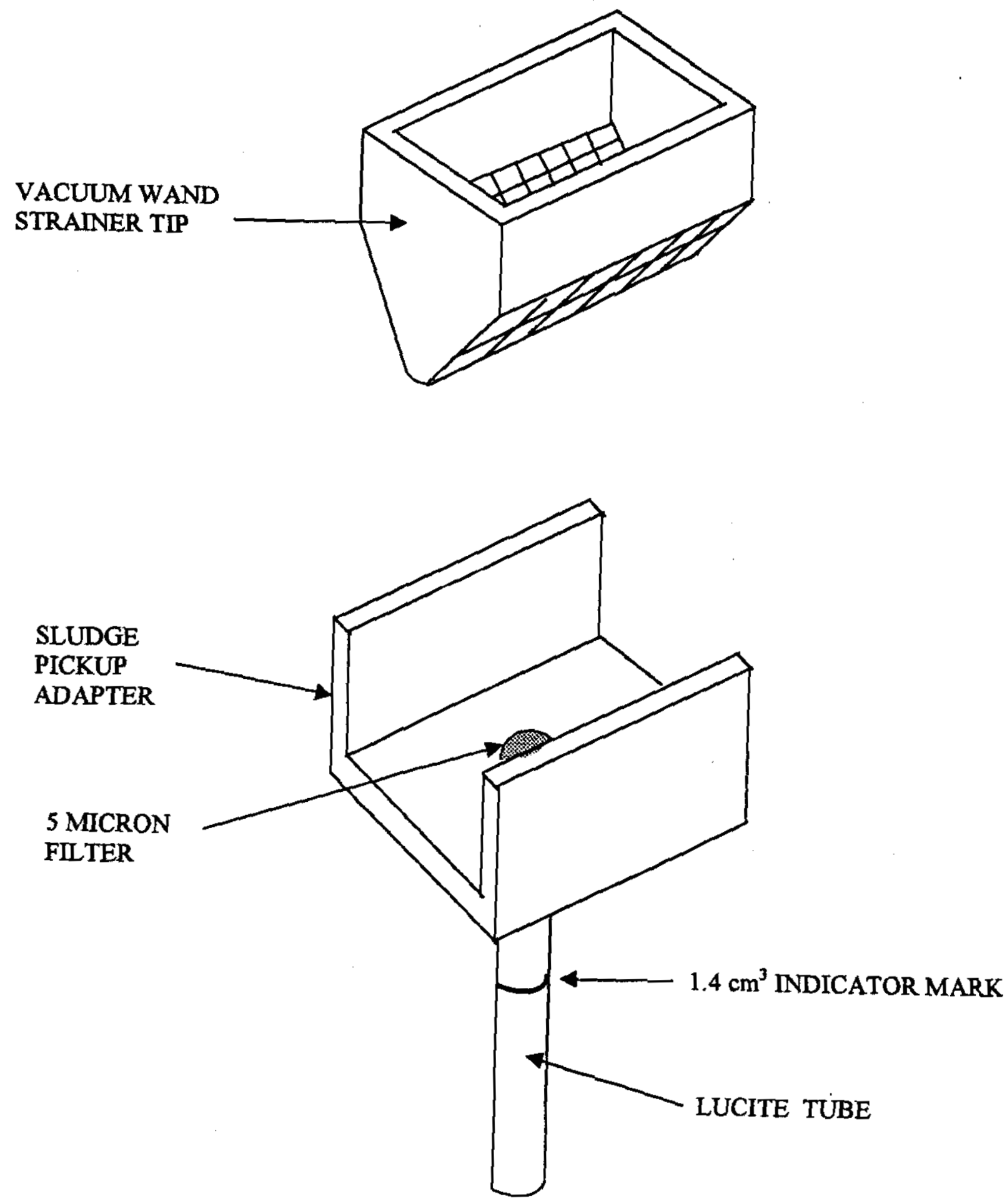


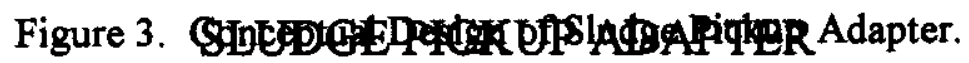
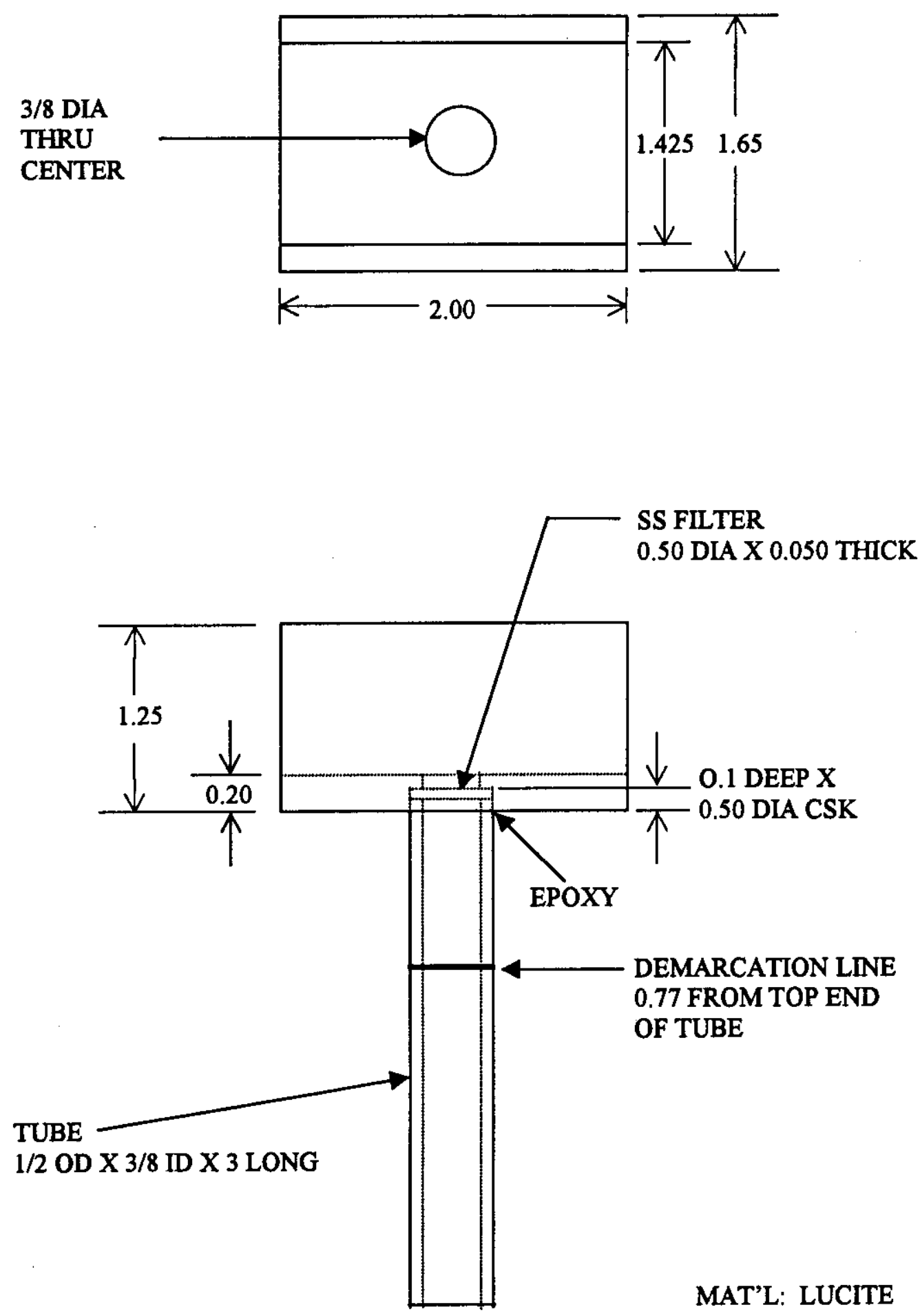
SNF-6109, Rev. 0

Figure 4. Scrap Grid Plate / Collection Tray.

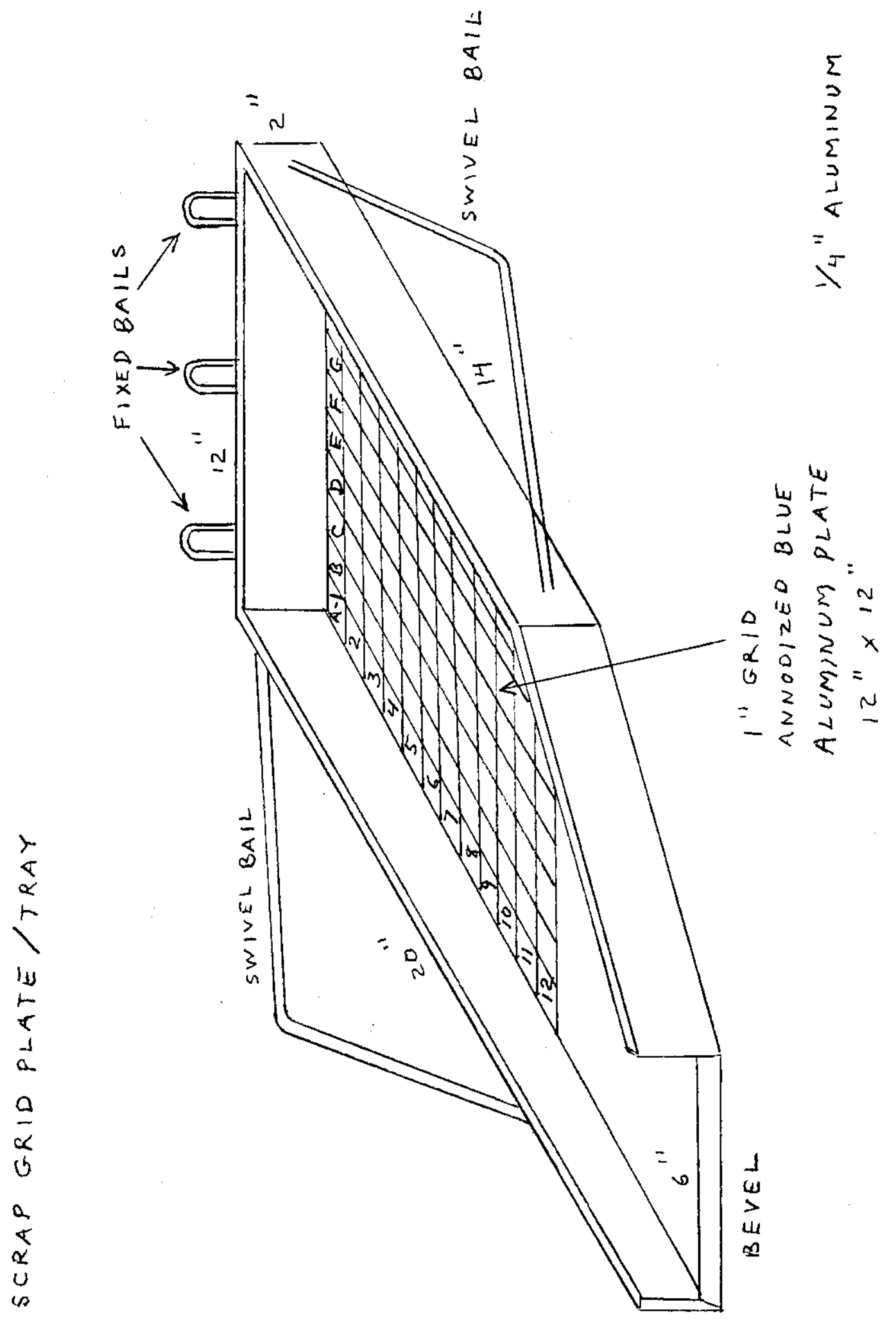


SNF-6109, Rev. 0

Figure 5. Scrap Canister Depth Measurement Tool.

SCRAP CANISTER

DEPTH MEASUREMENT

TOOL

BRACKET FASTENED

TO BASE AND RULE

$\longleftarrow 36^{\prime \prime}$ METAL

RULE WITH

$1 / 4$ "Divisions

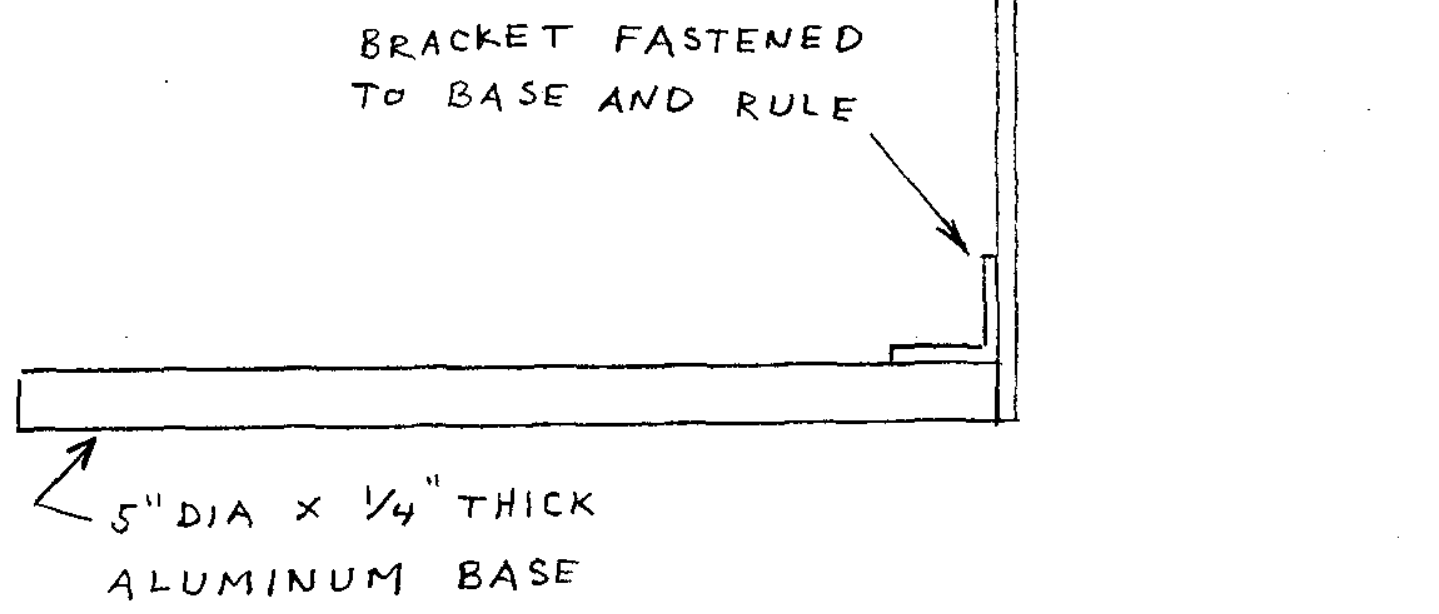




\section{DISTRIBUTION SHEET}

\begin{tabular}{|c|c|c|c|c|c|c|}
\hline \multirow{2}{*}{$\begin{array}{l}\text { To } \\
\text { Distribution }\end{array}$} & & \multirow{2}{*}{\multicolumn{3}{|c|}{$\begin{array}{l}\text { From } \\
\text { Process Engineering }\end{array}$}} & \multicolumn{2}{|l|}{ Page 1 of 1} \\
\hline & & & & & \multicolumn{2}{|l|}{ Date $3 / 31 / 00$} \\
\hline \multicolumn{5}{|c|}{ Project Title/Work Order } & \multicolumn{2}{|c|}{ EDT No. 629010} \\
\hline \multicolumn{5}{|c|}{$\begin{array}{l}\text { Engineering Work Plan for the Development of Phased Startup Initiative (PSI) } \\
\text { Phases } 3 \text { and } 4 \text { Test Equipment }\end{array}$} & \multicolumn{2}{|c|}{ ECN No. N/A } \\
\hline & Name & MSIN & $\begin{array}{l}\text { Text } \\
\text { With All } \\
\text { Attach. }\end{array}$ & $\begin{array}{l}\text { Text } \\
\text { Only }\end{array}$ & $\begin{array}{l}\text { Attach./ } \\
\text { Appendix } \\
\text { Only }\end{array}$ & $\begin{array}{l}\text { EDT/ECN } \\
\text { Only }\end{array}$ \\
\hline
\end{tabular}

Spent Nuclear Fuel Project

G. M. Davis

J. A. Dent

J. R. Frederickson

V. L. Hoefer

M. J. Langevin

W. C. Miller

J. W. Neskas

J. W. Oliver

A. L. Pajunen

A. L. Pitner

M. J. Schliebe

R. A. Sexton

J. L. Shelor

D. W. Smith

G. E. Stegen

J. A. Swenson

J. A. Tittle

P. A. Young

SNF Project

SNF Training

SNF Procedures

$\begin{array}{ll}\text { X3-80 } & \text { X } \\ \text { X3-65 } & \text { X } \\ \text { R3-86 } & \text { X } \\ \text { R3-86 } & \text { X } \\ \text { X3-76 } & \text { X } \\ \text { R3-11 } & \text { X } \\ \text { R3-86 } & \text { X } \\ \text { L6-13 } & \text { X } \\ \text { R3-86 } & \text { X } \\ \text { R3-86 } & \text { X } \\ \text { L6-13 } & \text { X } \\ \text { R3-86 } & \text { X } \\ \text { X3-71 } & \text { X } \\ \text { S2-48 } & \text { X } \\ \text { X3-76 } & \text { X } \\ \text { R3-11 } & \text { X } \\ \text { X3-80 } & \text { X } \\ \text { X3-88 } & \text { X } \\ \text { R3-11 } & \text { X } \\ \text { S2-45 } & \text { X } \\ \text { X3-86 } & \text { X }\end{array}$

